\title{
Reduction of microbial load in yellow alkaline noodle using optimized microwave and pulsed-UV treatment to improve storage stability
}

\author{
Anissa Soraya ${ }^{1} \cdot$ Shyan Yea Chay $^{2} \cdot$ Radhiah Shukri $^{3} \cdot$ Farinazleen Mohamad Ghazali $^{2} \cdot$ \\ Kharidah Muhammad ${ }^{2} \cdot$ Mohd Adzahan Noranizan $^{3} \cdot$ Roselina Karim $^{3}$ (i)
}

Revised: 9 January 2019/Accepted: 29 January 2019/Published online: 13 February 2019

(C) Association of Food Scientists \& Technologists (India) 2019

\begin{abstract}
Pulsed-UV is an emerging innovation in nonthermal processing and is scarcely explored. This study introduces a combined treatment of microwave and pulsedUV to reduce the microbial load in yellow alkaline noodle (YAN), a popular staple food among South East Asians that is easily perishable, without jeopardising its textural qualities. Results indicated that the combination of $5 \mathrm{~s}$ microwave (power $=900 \mathrm{~W}$; frequency $=2450 \mathrm{MHz}$ ) and $3.5 \mathrm{~J} / \mathrm{cm}^{2}$ pulsed-UV significantly reduced aerobic plate count and spore forming bacteria, from 637.5 to $50 \mathrm{CFU} / \mathrm{g}$ and 1500 to $100 \mathrm{CFU} / \mathrm{g}$, respectively. In terms of textural properties, even though significant changes were detected in hardness and springiness for treated YAN kept at ambient storage as compared to control, the alterations were not prominent. Based on these observations, it is concluded that a combined treatment of microwave and pulsed-UV successfully improved the shelf life of YAN at ambient storage by $50 \%$, from 1.0 day (control) to 1.5 days (treated sample) and by $140 \%$, from 2.0 to 4.8 weeks at chilled storage. Current study proves the potential of microwave + pulsed-UV, a "green" hurdle treatment, to extend the shelf life of preservative-free YAN without
\end{abstract}

Roselina Karim

rosaz@upm.edu.my

1 International University of Liaison Indonesia (IULI), IULIEco Campus, MyRepublic Plaza, The Breeze, BSD City 15345, Indonesia

2 Department of Food Science, Faculty of Food Science and Technology, Universiti Putra Malaysia, 43400 Serdang, Selangor, Malaysia

3 Department of Food Technology, Faculty of Food Science and Technology, Universiti Putra Malaysia (UPM), 43400 Serdang, Selangor, Malaysia causing major undesirable textural alterations on the noodle.

Keywords Yellow alkaline noodle $\cdot$ Microwave $\cdot$ PulsedUV $\cdot$ Microbial reduction $\cdot$ Storage study

\section{Introduction}

Yellow alkaline noodle (YAN) is popular in South East Asia countries like Malaysia, Indonesia and Singapore. It is made from wheat flour containing 11-12.5\% protein, water, salt (sodium chloride) and alkaline salt (sodium and potassium carbonate), and is usually parboiled before selling to consumers (Karim and Sultan 2015). Salt and alkaline are added to improve dough rheology and the eating quality of YAN, along with imparting a notable, unique flavour to the noodle ( $\mathrm{Li}$ et al. 2018). Without refrigeration, YAN have a shelf life of only 1-1.5 days due to its high moisture content, alkalinity and the presence of nutrient-dense compounds (Miskelly 1998). Addition of common chemicals such as benzoic acid, sorbic acid and propionic acid to preserve the noodle is not feasible, as these weak acids are ineffective at alkaline condition in YAN (Stratford et al. 2007). The only chemical with promising effect is boric acid but this acid has been prohibited by the Malaysian government, as well as in some other countries like Singapore, Thailand, China and United Kingdom, due to its severe side effects on humans including kidney failure, acute dysfunction of blood circulation and even death (Ang et al. 2010; Ministry of Health Malaysia 2012). Other techniques such as pasteurization and sterilization are deemed inappropriate to reduce microbial load in YAN because both treatments introduce heat to the noodle and result in further cooking. 
Maintaining the "parboiled" status of YAN is crucial to satisfy the consumers' perception that YAN should be semi-cooked. To date, lacking of proper preservation techniques urges the local researchers to look for suitable non-thermal, healthier "green" alternatives to increase the shelf-life of YAN.

Microwave treatment can effectively reduce microbial load in food products. In food industry, microwave treatment has been used to reduce microorganism load in milk (Tremonte et al. 2014), vegetables, fruits and grains (Vadivambal and Jayas 2007). Unlike pulsed-electric field that uses electric current as pulses, pulsed-UV uses light pulses to inactivate vegetative cells and spores (Dunn et al. 1995). Pulsed-UV is an emerging non-thermal technology with short treatment time, great flexibility and minimal energy costs (Oms-Oliu et al. 2010). Researches demonstrated effectiveness of pulsed-UV irradiation to significantly reduce Aspergillus spp. spores in several starchbased products, including corn meal (Jun et al. 2003) and malting barley (Zenklusen et al. 2018).

Hurdle technology is a combination of different food preservation techniques that improves the shelf life of products through a gentle yet effective approach (Singh and Shalini 2016). Combination of several techniques allows the usage of milder conditions as compared to that used during individual treatment alone. Consequently, the finished products demonstrate better quality in appearance and nutritional properties. To date, a hurdle that combines microwave and pulsed-UV treatment has not been applied anywhere to evaluate the efficacy to reduce microbial loads in any food products (Bhavya and Umesh Hebbar 2017), including YAN. Current study treats YAN with several combinations of microwave and pulsed-UV treatment which differ in time and heating power, then performs storage study using the optimum combination (optimization data not shown) to reduce microbial load in YAN at ambient and chilled temperatures, without causing major undesirable changes on its textural properties. Upon successful microbial reduction in YAN at laboratory scale, microwave + pulsed-UV treatment could be further upscaled to serve as "green" approach to preserve YAN commercially.

\section{Materials and methods}

\section{Materials}

Wheat flour was purchased from a local manufacturer (Federal Flour Mills Berhad, Malaysia). Palm cooking oil ("Seri Murni" brand) and polyethylene bags were purchased from local supermarket in Selangor, Malaysia. All ingredients used in noodle production were bought from Mei Lun Food Chemical Sdn. Bhd., Selangor, Malaysia.

\section{Noodle making process}

Noodles were prepared according to the method reported by Rosyid et al. (2011). Briefly, 100 parts of wheat flour, 34 parts of water, 1 part of cooking salt $(\mathrm{NaCl})$ and 1 part of alkaline salt (comprising of a mixture of $60 \%$ sodium carbonate, $\mathrm{Na}_{2} \mathrm{CO}_{3}$ and $40 \%$ potassium carbonate, $\mathrm{K}_{2} \mathrm{CO}_{3}$ ) were mixed together in a mixer (KitchenAid, model: 5K5SS, Michigan, USA) to form a crumbly mixture. The mixture was compressed into a dough slab [dimension: $600 \mathrm{~mm}(\mathrm{l}) \times 25 \mathrm{~mm}(\mathrm{w}) \times 1.6 \mathrm{~mm}(\mathrm{~h})]$ using a fabricated stainless steel compressor. The dough slab was passed through a pair of roller for seven successive sheeting steps. After the fifth sheeting step, the dough was allowed to rest for $15 \mathrm{~min}$ at room temperature $\left(28 \pm 2{ }^{\circ} \mathrm{C}\right)$ before further sheeting. The dough sheet was cut into noodles strands using a cutting roll after the seventh sheeting step. The noodle strands were parboiled for $50 \mathrm{~s}$ at $98 \pm 2{ }^{\circ} \mathrm{C}$ in boiling distilled water at a ratio of 1 part of noodles to 10 parts of water. They were then cooled immediately under running tap water for $1 \mathrm{~min}$, drained to remove surplus water and allowed to stand for $10 \mathrm{~min}$ at ambient temperature prior to coating with palm cooking oil $(3 \% \mathrm{w} / \mathrm{w})$. The noodles $(10.0 \mathrm{~g})$ were packed in individual polyethylene bags [dimension: $40.0 \mathrm{~cm}(\mathrm{l}) \times 12.7 \mathrm{~cm}(\mathrm{w})$ ] to serve as control or subjected to subsequent microwave/ pulsed-UV treatments.

\section{Experimental design for combined treatment (Microwave + pulsed-UV)}

Two-factor factorial design with four replications was adopted to study the simultaneous effect of different microwave heating times and pulsed-UV energy levels on the quality of YAN. A total of 20 runs were divided into two blocks, with each block containing two centre points. YAN, packed in polyethylene bags, was subjected to microwave treatment using a conventional microwave (Sharp Corp., model: R-958A, Sakai, Japan) with the frequency of $2450 \mathrm{MHz}$ and the power of $900 \mathrm{~W}$. The heating time was varied at 0,5 and $10 \mathrm{~s}$ at high power setting. Immediately after microwave treatment, YAN was subjected to pulsed-UV treatment (SteriBeam Systems GmbH, model: Steribeam SBS XeMatic-2L-A, Baden-Württemberg, Germany). The pulsed-UV power levels were varied at $0,3.5$ and $7.0 \mathrm{~J} / \mathrm{cm}^{2}$. These values were chosen based on preliminary study. Optimization procedure was then performed to identify the optimum microwave and pulse-UV parameters to reduce microbial load without posing major adverse textural effect on YAN. 


\section{Microbiological analysis of YAN}

Standard methods were used to enumerate microorganisms present in YAN samples at different sampling times (International Organization for Standardization 2003). Ten grams of YAN was mixed with $90 \mathrm{~mL}$ of sterile peptone water in a sterile stomacher bag, then homogenized for $60 \mathrm{~s}$ with a stomacher, followed by $10 \times$ dilution of the homogenized sample prior to plating. For spore forming bacteria analysis, homogenized sample was heated in water bath at $80{ }^{\circ} \mathrm{C}$ for $15 \mathrm{~min}$ to kill vegetative cells, then cooled to approximately $50{ }^{\circ} \mathrm{C}$ prior to $10 \times$ dilution. Aerobic plate count (APC) and spore forming bacteria count (SFB) were performed on plate count agar after incubation at $30{ }^{\circ} \mathrm{C}$ for $48 \mathrm{~h}$ and $72 \mathrm{~h}$, respectively; yeast and mould count (YMC) was conducted on Dichloran Rose Bengal Chloramphenicol agar after incubation at $30{ }^{\circ} \mathrm{C}$ for $72 \mathrm{~h}$ while total psychrophilic bacteria were assayed using plate count agar after incubation at $7{ }^{\circ} \mathrm{C}$ for 7 days. The microbial counts were expressed as $\log _{10} \mathrm{CFU} / \mathrm{g}$. All measurements were carried out in triplicates.

\section{Texture profile analysis}

Texture profile analysis of YAN was performed using Texture Analyzer (Stable Micro Systems, model: TA-XT2, Surrey, UK) equipped with Texture Exponent 32 software. Ten strands of noodle from each treatment were sampled. A $5 \mathrm{~kg}$ load cell and P/36R probe were used in this analysis. The texture analyzer settings were as follows: pre-test speed: $2.0 \mathrm{~mm} / \mathrm{s}$; test speed: $2.0 \mathrm{~mm} / \mathrm{s}$; post-test speed; $2.0 \mathrm{~mm} / \mathrm{s}$; mode: strain at $75 \%$; trigger force: $10 \mathrm{~g}$. Compression was performed twice to generate the force-time curve. Hardness, adhesiveness, springiness, cohesiveness and chewiness were measured, of which the latter three are unitless. Hardness $(\mathrm{g})$ is identified from the height of the first peak, which represents the maximum force during first probe compression; adhesiveness (gs) is measured from the negative area during probe retraction between two compressions; springiness is the time ratio between the start of second compression until second probe retraction to the start of first compression until first probe retraction; cohesiveness is calculated as the ratio between second peak area and first peak area; chewiness (g) is a term used for solid products and is calculated from the multiplication of hardness, cohesiveness and springiness. All measurements were carried out in triplicates.

\section{Storage study of YAN}

The storage experiment was conducted using a complete randomized design, with two replications per treatment. YAN was treated with optimum conditions (5 s microwave and $3.5 \mathrm{~J} / \mathrm{cm}^{2}$ pulsed-UV, optimization data not shown) and was stored at ambient condition $\left(28 \pm 2{ }^{\circ} \mathrm{C}\right)$ for 4 days and chilled condition $\left(4 \pm 2{ }^{\circ} \mathrm{C}\right)$ for 4 weeks. Samples were analysed in terms of moisture content, $\mathrm{pH}$, microbial load and textural properties to evaluate the effect of storage time and temperature on the quality of YAN. Moisture content was determined using air-oven method (44-15A) by (AACC International 2000). The $\mathrm{pH}$ of samples was measured using a $\mathrm{pH}$ meter (Mettler Toledo, model: SevenEasy S20, Columbus, USA). Microbial count and textural properties were evaluated using the method as described in Sects. 2.3 and 2.4.

\section{Statistical analysis}

Experimental data were analysed using one way ANOVA (Analysis of Variance) at a 95\% confidence interval $(P$ $\leq 0.05$ ). Tukey's test was performed to evaluate the effect of storage time on the moisture content, $\mathrm{pH}$ and textural properties within the same sample at different storage time. Paired $t$ test was conducted to evaluate the effect of treatment (i.e. microwave + pulsed-UV) on the moisture content, $\mathrm{pH}$ and textural properties of control and treated samples. All statistical analysis was performed using Minitab $^{\circledR}$ Release 14 Statistical Software (Minitab Inc, State College, USA).

\section{Results and discussion}

\section{Effects of microwave + pulsed-UV on the microbiological quality and textural properties of YAN}

Current study investigates the effects of combined microwave exposure times (5 and $10 \mathrm{~s}$ ) and pulsed-UV energy levels $\left(3.5\right.$ and $\left.7.0 \mathrm{~J} / \mathrm{cm}^{2}\right)$ to reduce the microbial content in YAN without causing major undesirable textural changes.

From Table 1, all treatments reduced the aerobic plate count (APC) and spore forming bacteria (SFB), but failed to reduce yeast and mould count (YMC). These proved the remarkable bactericidal activity of microwave + pulsedUV treatment in YAN. The bactericidal effect from pulsed$\mathrm{UV}$ is due to the photothermal and photochemical reactions that occur when UV light comes into contact with bacterial cells. Photothermal mechanism kills bacteria by overheating the cells and causes the internal cell materials to swell and burst while photochemical reaction destroys microbial cells by altering its nucleic acid structure to impose a functionality loss (Abida et al. 2014).

Ideally, YAN should be firm, smooth and springy (Ito et al. 2007). Hardness is the force to incise the noodle and 
Table 1 The microbiological quality (CFU/g) and texture profile for yellow alkaline noodle treated with different combinations of microwave and pulsed-UV treatments

\begin{tabular}{|c|c|c|c|c|c|c|c|c|c|c|}
\hline & \multicolumn{2}{|c|}{ Treatment } & \multicolumn{3}{|c|}{$\begin{array}{l}\text { Microbiological quality } \\
\text { (CFU/g) }\end{array}$} & \multicolumn{5}{|l|}{ Texture profile } \\
\hline & $\begin{array}{l}\mathrm{mw} \\
(\mathrm{s})\end{array}$ & $\begin{array}{l}\text { puv }(\mathrm{J} / \\
\left.\mathrm{cm}^{2}\right)\end{array}$ & APC & YMC & SFB & Hardness (g) & $\begin{array}{l}\text { Adhesiveness } \\
\text { (gs) }\end{array}$ & Springiness & Cohesiveness & Chewiness (g) \\
\hline 1 & 0 & 0 & $637.5^{\mathrm{a}}$ & $162.5^{\mathrm{a}}$ & $1500.0^{\mathrm{a}}$ & $2389.8^{c} \pm 61.3$ & $19.07^{\mathrm{b}} \pm 0.18$ & $1.00^{\mathrm{c}} \pm 0.02$ & $0.64^{\mathrm{b}} \pm 0.01$ & $1525.3^{c} \pm 37.9$ \\
\hline 2 & 0 & 7 & $112.5^{\mathrm{b}}$ & $37.5^{\mathrm{a}}$ & $1000.0^{\mathrm{a}}$ & $2429.5^{\mathrm{bc}} \pm 2.5$ & $18.39^{\mathrm{b}} \pm 0.33$ & $1.00^{\mathrm{c}} \pm 0.02$ & $0.65^{\mathrm{b}} \pm 0.01$ & $1583.3^{\mathrm{c}} \pm 49.6$ \\
\hline 3 & 5 & 3.5 & $50.0^{\mathrm{b}}$ & $100.0^{\mathrm{a}}$ & $100.0^{\mathrm{b}}$ & $2507.8^{\mathrm{b}} \pm 35.9$ & $21.14^{\mathrm{a}} \pm 0.88$ & $1.09^{c} \pm 0.21$ & $0.65^{\mathrm{b}} \pm 0.01$ & $1794.0^{\mathrm{c}} \pm 82.4$ \\
\hline 4 & 10 & 0 & $37.5^{\mathrm{b}}$ & $100.0^{\mathrm{a}}$ & $162.5^{\mathrm{b}}$ & $2873.5^{\mathrm{a}} \pm 45.0$ & $9.16^{\mathrm{c}} \pm 0.26$ & $2.65^{\mathrm{b}} \pm 0.06$ & $0.71^{\mathrm{a}} \pm 0.01$ & $6394.3^{b} \pm 280.3$ \\
\hline 5 & 10 & 7 & $37.5^{\mathrm{b}}$ & $25.0^{\mathrm{a}}$ & $50.0^{\mathrm{b}}$ & $2910.0^{\mathrm{a}} \pm 57.9$ & $9.28^{c} \pm 0.34$ & $6.26^{\mathrm{a}} \pm 0.31$ & $0.70^{\mathrm{a}} \pm 0.01$ & $12,879.0^{\mathrm{a}} \pm 762.7$ \\
\hline
\end{tabular}

Mean values with different superscript letters in the same column are significantly different $(P<0.05)$; APC, YMC and SFB microbial counts represent crude estimation of colonies and are reported without standard deviations; all textural values were reported as mean \pm SD from triplicate readings

$m w$ Microwave, puv pulsed-UV, APC aerobic plate count, $Y M C$ yeast and mould count, $S F B$ spore forming bacteria

is recorded as the maximum force during the first compression cycle in texture profile analysis (Souza et al. 2002). Springiness is the elasticity felt by the mouth when chewing and it indicates the degree of recovery after the first bite (Wheat Marketing Centre 2008). Adhesiveness, or stickiness, is defined as the force required to remove the noodle that adheres to the palate during eating ( $\mathrm{Li}$ et al. 2017) and represents an important parameter for Asian noodles. Adhesiveness in noodles is an undesirable attribute, because it means the noodles tend to "stick" inside the mouth before swallowing. Microwave at $10 \mathrm{~s}$, be it single treatment or coupled with pulsed-UV, posed significant textural changes to the noodles. Hardness, springiness and chewiness were significantly increased $(P \leq 0.05)$ while adhesiveness and cohesiveness were significantly decreased $(P \leq 0.05)$ when microwave heating was applied. The textural changes were even more prominent for YAN treated with microwave + pulsed-UV, whereby the springiness leaped from 2.65 to 6.26 (unitless) and chewiness leaped from 6394.3 to $12,879.0 \mathrm{~g}$ when compared to sole microwave treatment. These observations were due to the loss of moisture in YAN as a result of temperature increment during microwave heating which evaporates water molecules and retrogradation process which expel water through syneresis when the starch polymers rearrange (Hoover et al. 2010).

Different treatment combinations produced different microbiological and textural effects on YAN, thus optimization was performed to identify the optimum microwave and pulsed-UV parameters which reduced microbial load in YAN without compromising its textural quality. The optimum combined treatment for YAN was $5 \mathrm{~s}$ microwave heating followed by $3.5 \mathrm{~J} / \mathrm{cm}^{2}$ pulsed-UV treatment. These parameters were validated after fitting the actual experimental data into the predicted
microwave*pulsed-UV interaction model, of which four significantly affected terms, i.e. total aerobic mesophilic bacteria, springiness, cohesiveness and chewiness, were evaluated. The statistical analysis showed that there was no significant difference $(P>0.05)$ between the predicted and actual data for all four parameters (data not shown), proving the validity of $5 \mathrm{~s}$ of microwave followed by $3.5 \mathrm{~J} /$ $\mathrm{cm}^{2}$ pulsed-UV treatments to produce YAN with desirable qualities. Thus, these parameters were chosen for storage study.

\section{Storage study}

\section{Moisture content and $\mathrm{pH}$ value of YAN}

Moisture and $\mathrm{pH}$ are two key factors that affect the microbiological quality and textural profile of YAN, which in turn determine the shelf life. The moisture content of YAN during storage at ambient and chilled conditions is depicted in Table 2. Based on paired $t$ test, there was no significant difference $(P>0.05)$ between the overall moisture content for control and treated YAN, be it at ambient or chilled conditions. However, when comparison is made within the same sample (either control or treated) across different storage time, significant differences $(P$ $\leq 0.05$ ) were detected. Storage at ambient temperature showed a significant increase in moisture content over time, in both control and treated samples. The result is similar to that reported by Ali et al. (2008) who observed increased moisture content in cooked rice during storage at ambient temperature. The increase is suspected to be due to the migration of moisture, by diffusion, from a high relative humidity environment $(\approx 80 \%)$ to low moisture YAN through the packaging material. The opposite observation was made for YAN stored at chilled condition, whereby the 
Table 2 The $\mathrm{pH}$ value and moisture of yellow alkaline noodle during storage at ambient and chilled conditions

\begin{tabular}{|c|c|c|c|c|c|}
\hline \multirow[t]{2}{*}{ Storage condition } & \multirow[t]{2}{*}{ Storage time } & \multicolumn{2}{|c|}{ Moisture content $(\%)$} & \multicolumn{2}{|l|}{$\mathrm{pH}$ value } \\
\hline & & Control & Treated YAN & Control & Treated YAN \\
\hline \multirow[t]{6}{*}{ Ambient temperature $\left(28 \pm 2{ }^{\circ} \mathrm{C}\right)$} & 0 day & $52.3^{\mathrm{a}} \pm 0.5$ & $53.0^{\mathrm{a}} \pm 0.5^{\mathrm{a}}$ & $9.97^{\mathrm{a}} \pm 0.04$ & $10.04^{\mathrm{a}} \pm 0.00$ \\
\hline & 1 day & $52.4^{\mathrm{a}} \pm 0.2$ & $53.1^{\mathrm{a}} \pm 0.7$ & $9.78^{\mathrm{a}} \pm 0.01$ & $9.77^{\mathrm{b}} \pm 0.01$ \\
\hline & 2 day & $55.4^{\mathrm{b}} \pm 0.1$ & $55.6^{\mathrm{b}} \pm 0.0$ & $9.59^{\mathrm{a}} \pm 0.02$ & $9.76^{\mathrm{b}} \pm 0.01$ \\
\hline & 3 day & $55.6^{\mathrm{b}} \pm 0.1$ & $55.6^{\mathrm{b}} \pm 0.1$ & $8.36^{\mathrm{b}} \pm 0.26$ & $9.56^{\mathrm{c}} \pm 0.09$ \\
\hline & 4 day & $55.6^{\mathrm{b}} \pm 0.0$ & $55.6^{\mathrm{b}} \pm 0.0$ & $7.56^{\mathrm{c}} \pm 0.02$ & $8.84^{\mathrm{d}} \pm 0.01$ \\
\hline & $P$-value for $t$ test & 0.646 & & 0.139 & \\
\hline \multirow[t]{6}{*}{ Chilled temperature $\left(4 \pm 2{ }^{\circ} \mathrm{C}\right)$} & 0 week & $52.3^{\mathrm{a}} \pm 0.3$ & $53.0^{\mathrm{a}} \pm 0.4$ & $9.97^{\mathrm{a}} \pm 0.04$ & $10.04^{\mathrm{a}} \pm 0.00$ \\
\hline & 1 week & $52.2^{\mathrm{a}} \pm 0.2$ & $52.6^{\mathrm{a}} \pm 0.1$ & $9.75^{\mathrm{ab}} \pm 0.01$ & $9.77^{\mathrm{b}} \pm 0.01$ \\
\hline & 2 week & $52.0^{\mathrm{a}} \pm 0.3$ & $52.1^{\mathrm{a}} \pm 0.4$ & $9.54^{\mathrm{b}} \pm 0.25$ & $9.76^{\mathrm{b}} \pm 0.00$ \\
\hline & 3 week & $51.9^{\mathrm{a}} \pm 0.2$ & $51.9^{\mathrm{a}} \pm 0.4$ & $9.54^{\mathrm{b}} \pm 0.04$ & $9.73^{b} \pm 0.02$ \\
\hline & 4 week & $45.7^{\mathrm{b}} \pm 0.1$ & $46.2^{\mathrm{b}} \pm 0.3$ & $9.54^{\mathrm{b}} \pm 0.13$ & $9.66^{\mathrm{c}} \pm 0.03$ \\
\hline & $P$-value for $t$ test & 0.767 & & 0.139 & \\
\hline
\end{tabular}

All values were reported as mean \pm SD from triplicate readings; mean values with different superscript letters in the same column are significantly different $(P<0.05)$

moisture content for control and treated samples decreased at the 4th week of storage. The moisture loss was mostly due to retrogradation of gelatinized starch in YAN. Upon cooling at chilled temperature, the starch network (amylose and amylopectin) interact to form a more ordered structure. This spontaneous rearrangement process of starch is accompanied by water exudation or syneresis (Hoover et al. 2010), where water molecules are consistently expelled from the starch network, thus reducing the moisture content in YAN.

The $\mathrm{pH}$ values of YAN are shown in Table 2. Paired $t$ test showed that the $\mathrm{pH}$ of control and treated YAN were not significantly different $(P>0.05)$ at both ambient and chilled conditions. When comparison is made within the same sample (either control or treated) at different storage time, the $\mathrm{pH}$ values in all samples decreased significantly $(P \leq 0.05)$ at both temperatures. This phenomenon is most likely due to the microbial activity that is taking place in the noodles. According to Garbutt (1997), microbial activity might alter the $\mathrm{pH}$ profile of a food product. YAN is rich in carbohydrate and protein. These macronutrients provide plentiful carbon, hydrogen, oxygen and nitrogen to support rapid microbial growth. Acids are produced as the microbial metabolites which in turn lowers the $\mathrm{pH}$ (Ray and Bhunia 2007). YAN stored at ambient temperature showed a more prominent decrease in $\mathrm{pH}$ than that stored at chilled temperature. This is because at chilled condition, the rate of microorganism growth and activity were slower than that at ambient condition. Lower metabolism activity resulted in lesser production of acid as metabolites, thus lesser changes in $\mathrm{pH}$ for chilled samples compared to ambient samples.

\section{Microbiological quality of YAN}

Microbiological quality is one of the most critical parameters in determining the shelf life of YAN. According to Food and Drug Administration of Philippines (2013), the acceptable limit for aerobic plate count (APC) and yeast and mould count (YMC) in wet, uncooked noodle is $5 \mathrm{log}$ $\mathrm{CFU} / \mathrm{g}$. The microbiological limit from FDA Philippines is referenced because it is the most updated and relevant standard to YAN, as this noodle is frequently consumed in South East Asian countries. Comparison of YAN with renowned microbiological standards for pasta is not practical because YAN is parboiled (fresh and wet) while pasta is in dried form.

The level of $5 \log \mathrm{CFU} / \mathrm{g}$ was selected as the cut-off point to assess the microbial quality in both control and microwave + pulsed-UV treated YAN. Figure $1 \mathrm{a}$ and $\mathrm{b}$ show the APC in YAN stored at ambient and chilled conditions, respectively. The initial count of $1.7 \mathrm{log}$ CFU/g in treated YAN was lower than that in control (3.1 log $\mathrm{CFU} / \mathrm{g}$ ), at both temperatures, proving the feasibility of microwave + pulsed-UV treatment to reduce the initial microbial load in YAN. At ambient temperature, the bacterial count in control and treated YAN reached $5 \log \mathrm{CFU} /$ $\mathrm{g}$ at 1.0 day and 1.5 days, respectively, indicating that microwave + pulsed-UV treatment could extend the shelf life of YAN from 1.0 to 1.5 days at ambient storage. Growth of aerobic, mesophilic bacteria at ambient is very rapid due to the favourable environmental temperature, as well as the nature of YAN that is high in moisture and rich in nutrients, such as carbohydrate and protein, that supports rapid microbial growth. Even though the optimum growth 

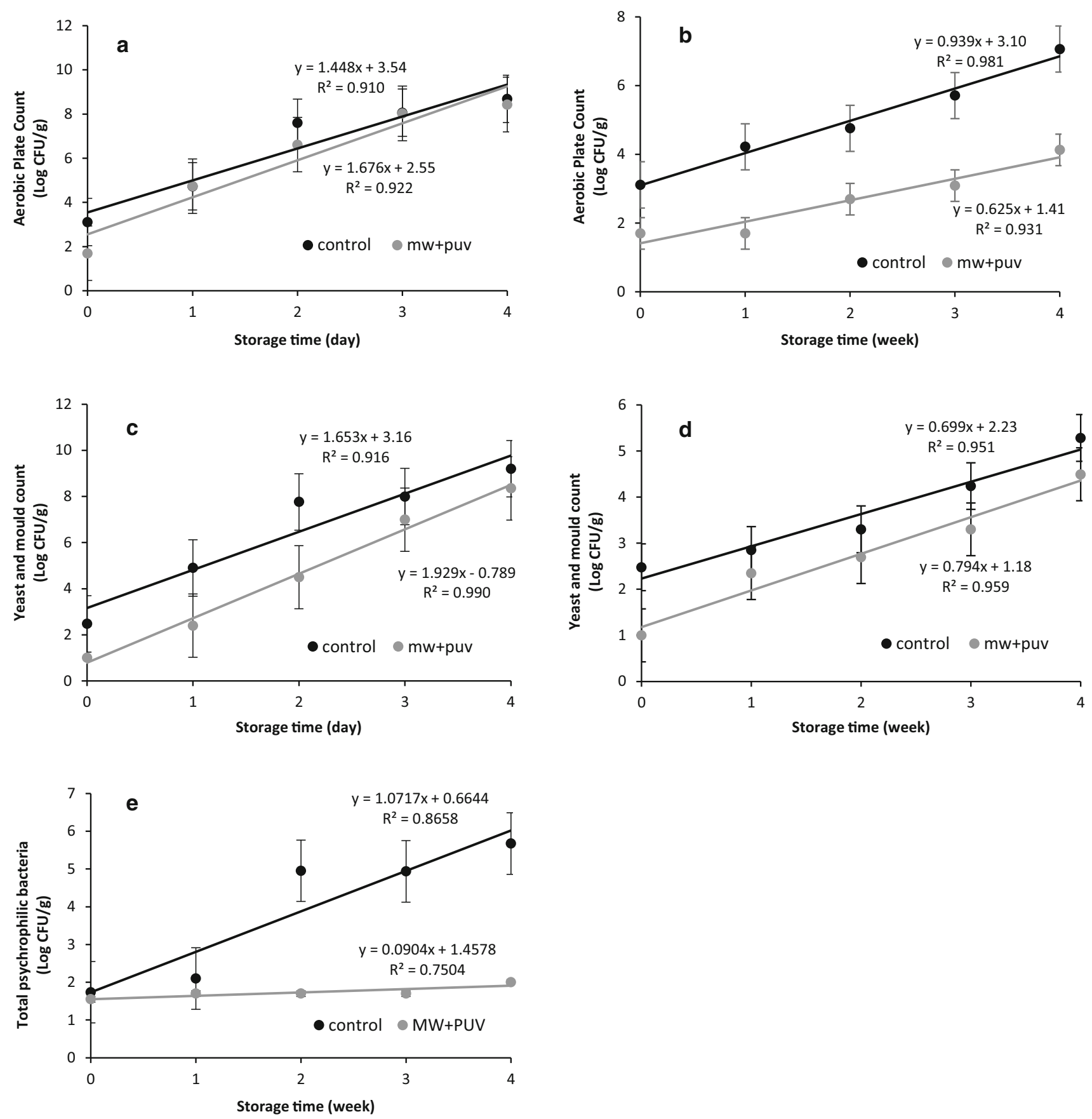

Fig. 1 Microbial profile for yellow alkaline noodle: Aerobic plate count at $\mathbf{a}$ ambient and $\mathbf{b}$ chilled temperature; Yeast and mould count at $\mathbf{c}$ ambient and $\mathbf{d}$ chilled temperature; Total psycrophilic bacteria at e chilled temperature. All bacterial count were reported in $\log \mathrm{CFU} / \mathrm{g}$.

temperature for aerobic, mesophilic bacteria ranges between 35 and $40{ }^{\circ} \mathrm{C}$, these bacteria could grow well in a wide range of temperature, i.e. between 10 and $45^{\circ} \mathrm{C}$ (McCall et al. 2009), justifying the high APC count in YAN stored at ambient temperature $\left(28^{\circ} \mathrm{C}\right)$. On the other hand, the bacterial count for control and treated YAN at chilled storage reached $5 \log \mathrm{CFU} / \mathrm{g}$ at 2.0 weeks and

Bars represent standard deviation from triplicate readings. Ambient temperature $=28 \pm 2{ }^{\circ} \mathrm{C} ; \quad$ Chilled temperature $=4 \pm 2{ }^{\circ} \mathrm{C}$; $\mathrm{mw}+$ puv $=$ microwave and pulsed-UV treatment

5.7 weeks, respectively, based on the extrapolated calculation from mathematical model in Fig. 1b. This finding indicated that microwave + pulsed-UV treatment successfully suppressed the aerobic bacterial growth in YAN to a level below the critical cut-off point $(5 \log \mathrm{CFU} / \mathrm{g})$ up to 5.7 weeks under chilled condition, as compared to untreated YAN which reached the limit at 2.0 weeks. 
The proliferation of yeast and mould in YAN during storage at ambient and chilled temperatures are shown in Fig. 1c and d. YAN treated with microwave + pulsed-UV had a significantly lower initial yeast and mould count (YMC) (1.0 log CFU/g) compared to control (2.5 log CFU/ $\mathrm{g}$ ), showing the potential of microwave + pulsed-UV to reduce initial YMC in samples. At ambient temperature, YMC reached the cut-off limit (5 log CFU/g) at 1.1 days for control and 3.0 days for treated sample. In contrast, a slower growth rate of yeast and mould was observed for chilled samples whereby the YMC reached the cut-off limit at 4.0 weeks for control and 4.8 weeks for treated sample (based on extrapolation from mathematical equations in Fig. 1d). To determine the shelf life of YAN at ambient and chilled conditions, the time for YAN to reach APC and YMC spoilage limit at both conditions were considered. At ambient, APC reached the spoilage limit at 1.5 days while YMC reached the limit at 3.0 days. At chilled condition, APC reached the limit at 5.7 weeks and YMC reached the limit at 4.8 weeks. The microbial parameter (APC or YMC) with the shorter shelf-life dictates the shelf life of YAN, because a food is considered spoilt when the first microbial parameter reaches its limit. Based on this, the shelf life of YAN stored at ambient was improved from 1.0 day (control) to 1.5 days while that stored at chilled condition was improved from 2.0 weeks (control) to 4.8 weeks. These results depict the ability of hurdle technology (microwave + pulsed-UV) to extend the shelf life of YAN by $50 \%$ for ambient sample and by $140 \%$ for chilled sample.

Psychrophilic pathogen is one of the most neglected areas in food microbiological safety (Garima 2016) because refrigeration is frequently perceived to be superiorly effective to prevent microbial growth. However, it should be given consideration that psychrophile is very likely to thrive under refrigerated conditions. Current study evaluates the growth of psychrophilic bacteria in chilled YAN. From Fig. 1e, starting from week 2 onwards, the total psychrophilic bacteria in treated YAN was significantly lower than control and it maintained far below the microbiological limit of $6 \log \mathrm{CFU} / \mathrm{g}$, which is the acceptable limit for psychrophilic bacteria in chilled fish previously defined by Mol et al. (2007). The limit for chilled fish is cited because there is no available acceptable limit for psychrophiles from established food standards and regulations. Figure 1e shows that the combined treatment of microwave + pulsed-UV was effective in reducing the psychrophilic bacteria load in YAN. This result was in agreement with Yilmaz et al. (2002) which proved that microwave heating could reduce the psychrophilic bacteria load in meatball. Storage at chilled condition could retard the growth of total aerobic mesophilic bacteria, yeast and mould, as well as psychrophilic bacteria as compared to storage at ambient temperature. Refrigeration retards the growth of microorganisms by lowering the metabolism rate of most microorganisms as a result of slower enzyme activity, thus maintaining the noodles' freshness for a longer time compared to ambient condition.

The current findings clearly show the ability of a combined treatment (microwave + pulsed-UV) to successfully improve the shelf life of YAN, at both ambient and chilled temperatures. At ambient storage, the shelf life of YAN extends by $50 \%$, from 1.0 to 1.5 days, whereas at chilled storage, the shelf life extends by $140 \%$, from 2.0 to 4.8 weeks.

\section{Textural profile of YAN}

Noodle dough is a complex food matrix with multiple interacting components which contribute to the overall dough rheology, ultimately affecting the noodle quality $(\mathrm{Li}$ et al. 2018). The textural profile of YAN during ambient and chilled storage is shown in Table 3. The textural profile of control YAN on the 4th day of storage at ambient temperature was unreadable due to spoilage of sample that led to a mushy texture. At both storage temperatures, hardness was negatively correlated with moisture content. For ambient YAN, moisture increased but the noodle hardness decreased, i.e. the noodles soften. Contrary, for chilled YAN, moisture decreased throughout the 4-weeks storage period but the hardness values increased. It was deduced that chilled storage would cause a significant loss of moisture in the noodles and lead to texture hardening, possibly due to starch retrogradation that expels water molecules from the noodle matrix. The increment in hardness values for YAN was in line with that reported by Singh et al. (2002), who observed an increment in hardness over storage for potato starch and corn starch noodles.

Based on paired $t$ test, a combined treatment of microwave + pulsed-UV did not cause any significant changes $(P>0.05)$ in the textural profile of ambient YAN, except in terms of hardness and springiness, as indicated by their respective $P$-values of 0.001 and 0.005 (Table 3). YAN is generally sold in parboiled state in South East Asia. The noodle requires further cooking (for example blanching, stir-frying) before consumption. The textural changes may not reflect the final sensory properties and is considered less relevant at this point of time. For other textural parameters including adhesiveness, cohesiveness and chewiness, particularly that for YAN stored at ambient temperature, difference between control and treated sample was not significant but difference across days within the same sample were significant, indicating that the textural changes is due to time factor rather than treatment factor. One possible explanation would be the high microbial 


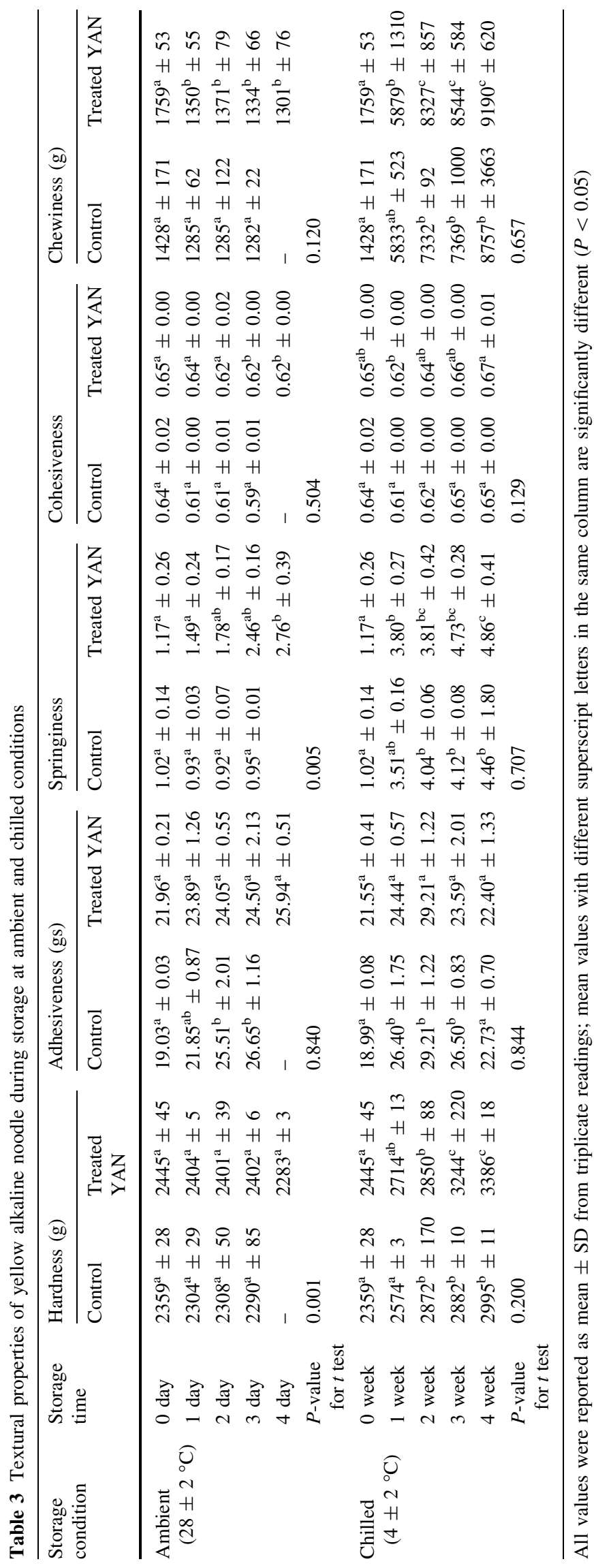


activity which involves consistent break down of macromolecules such as carbohydrate, protein and lipid into simpler compound, resulting in the alteration of noodles structure with increasing storage time.

For chilled sample, YAN treated with microwave + pulsed-UV did not show significant difference $(P>0.05)$ from control in all textural properties throughout the 4-week course of storage. However, when comparison was made within the same samples (either control or treated) across different weeks, significant changes were detected in hardness, springiness and chewiness of the noodles. Hardness increased from 2359 to $2995 \mathrm{~g}$ for control and from 2445 to $3386 \mathrm{~g}$ for treated sample, while springiness increased from 1.02 to 4.46 for control and from 1.17 to 4.86 for treated sample. Chewiness increased tremendously from 1428 to $8757 \mathrm{~g}$ for control and from 1759 to $9190 \mathrm{~g}$ for treated sample from week 0 to week 4 . Since textural changes were detected in untreated samples (i.e. control), the changes were due to chilled temperature and not microwave + pulsed-UV treatment. This is because chilling promotes starch retrogradation. Baik et al. (1997) found that retrogradation took place more rapidly in rice stored at $4{ }^{\circ} \mathrm{C}$ compared to rice stored at room temperature. Frei et al. (2003) also observed that $4{ }^{\circ} \mathrm{C}$ is the temperature where retrogradation occurred most rapidly in rice starch. Based on these, chilling of YAN that is high in carbohydrate contributes towards the occurrence of retrogradation and affects the final textural property of the noodles. However, this may not be a major concern in terms of sensory properties because parboiled YAN is likely to be cooked again before consumption.

\section{Conclusion}

Current study demonstrates the potential of combining microwave treatment with pulsed-UV, an emerging technology, to reduce the microbial load in YAN to produce a preservative-free noodle. A treatment combination of $5 \mathrm{~s}$ microwave $+3.5 \mathrm{~J} / \mathrm{cm}^{2}$ pulsed-UV successfully extends the shelf life of YAN by 50\%, from 1.0 to 1.5 days, at ambient storage and by $140 \%$, from 2.0 to 4.8 weeks, at chilled storage, without posing major undesirable changes on the textural properties of the noodles. This hurdle treatment demonstrates bright commercial prospective as a "green" approach in the manufacture of preservative-free YAN with extended shelf-life.

Acknowledgements The authors gratefully acknowledge the financial support from Ministry of Science, Technology and Innovation (MOSTI), Malaysia, for funding this study under ScienceFund (Grant number: 05-01-04-SF0750). Sincere gratitude is also dedicated to Dr. Alexander Wekhof from SteriBeam Systems GmbH, who kindly sold us the pulsed-UV machine at a discounted price for research purposes.

\section{References}

AACC International (2000) Method 44-15A (Moisture: air oven method). Approved methods of analysis. American Association of Cereal Chemists Inc, Minnesota

Abida J, Rayees B, Masoodi F (2014) Pulsed light technology: a novel method for food preservation. Int Food Res J 21:839-848

Ali M, Hasan A, Islam M (2008) Study on the period of acceptability of cooked rice. J Bangladesh Agric Univ 6:401-408

Ang SS, Salleh AB, Abu Bakar F, Yusof NA, Abdulamir AS, Lee YH (2010) Risk and health effect of boric acid. Am J Appl Sci 7:620-627

Baik MY, Kim KJ, Cheon KC, Ha YC, Kim WS (1997) Recrystallization kinetics and glass transition of rice starch gel system. J Agric Food Chem 45:4242-4248

Bhavya M, Umesh Hebbar H (2017) Pulsed light processing of foods for microbial safety. Food Qual Saf 1:187-202

Dunn J, Ott T, Clark W (1995) Pulsed-light treatment of food and packaging. Food Technol 49:95-98

Food and Drug Administration of Philippines (2013) Guidelines for the assessment of microbiological quality of processed food. https://ww2.fda.gov.ph/attachments/article/17218/FC2013-010. pdf. Accessed 31 July 2018

Frei M, Siddhuraju P, Becker K (2003) Studies on the in vitro starch digestibility and the glycemic index of six different indigenous rice cultivars from the Philippines. Food Chem 83:395-402

Garbutt J (1997) Essentials of food microbiology. Taylor \& Francis Group, Oxfordshire

Garima U (2016) Psychrophilic pathogens: potential risk for food borne illness. Res J Recent Sci 5:50-52

Hoover R, Hughes T, Chung H, Liu Q (2010) Composition, molecular structure, properties, and modification of pulse starches: a review. Food Res Int 43:399-413

International Organization for Standardization (2003) ISO 4833: microbiology of food and animal feeding stuffs: horizontal method for the enumeration of microorganisms: colony-count technique at $30{ }^{\circ} \mathrm{C}$. International Organization for Standardization, Geneva

Ito M, Ohta K, Nishio Z, Tabiki T, Hashimoto N, Funatsuki W, Miura H, Yamauchi H (2007) Quality evaluation of yellow alkaline noodles made from the Kitanokaori wheat cultivar. Food Sci Technol Res 13:253-260

Jun S, Irudayaraj J, Demirci A, Geiser D (2003) Pulsed UV-light treatment of corn meal for inactivation of Aspergillus niger spores. Int J Food Sci Technol 38:883-888

Karim R, Sultan MT (2015) Yellow alkaline noodles: an introduction. In: Yellow alkaline noodles. Springer, Cham, pp 7-8

Li M, Dhital S, Wei Y (2017) Multilevel structure of wheat starch and its relationship to noodle eating qualities. Compr Rev Food Sci Food Saf 16:1042-1055

Li M, Sun QJ, Han CW, Chen HH, Tang WT (2018) Comparative study of the quality characteristics of fresh noodles with regular salt and alkali and the underlying mechanisms. Food Chem 246:335-342

McCall D, Stock D, Achey P (2009) 11th hour: introduction to microbiology. Wiley, New Jersey

Ministry of Health Malaysia (2012) What you should know about boric acid? http://www.myhealth.gov.my/en/what-you-shouldknow-about-boric-acid/. Accessed 31 October 2018

Miskelly DM (1998) Modern noodle based foods-raw material needs In: Pacific people and their food. American Association of Cereal Chemist, Inc., Minnesota, pp 123-142

Mol S, Erkan N, Uecok D, Tosun ŞY (2007) Effect of psychrophilic bacteria to estimate fish quality. J Muscle Foods 18:120-128 
Oms-Oliu G, Martín-Belloso O, Soliva-Fortuny R (2010) Pulsed light treatments for food preservation: a review. Food Bioprocess Technol 3:13-23

Ray B, Bhunia A (2007) Fundamental food microbiology. CRC Press, Florida

Rosyid TA, Karim R, Adzahan NM, Ghazali FM (2011) Antibacterial activity of several Malaysian leaves extracts on the spoilage bacteria of yellow alkaline noodles. Afr J Microbiol Res 5:898-903

Singh S, Shalini R (2016) Effect of hurdle technology in food preservation: a review. Crit Rev Food Sci Nutr 56:641-649

Singh N, Singh J, Singh Sodhi N (2002) Morphological, thermal, rheological and noodle-making properties of potato and corn starch. J Sci Food Agric 82:1376-1383

Souza EJ, Graybosch RA, Guttieri MJ (2002) Breeding wheat for improved mill and baking quality. In: Quality improvement in field crops. The Haworth Press Inc., New York, pp 39-74

Stratford M, Plumridge A, Archer DB (2007) Decarboxylation of sorbic acid by spoilage yeasts is associated with the PAD1 gene. Appl Environ Microbiol 73:6534-6542
Tremonte P, Tipaldi L, Succi M, Pannella G, Falasca L, Capilongo V, Coppola R, Sorrentino E (2014) Raw milk from vending machines: effects of boiling, microwave treatment, and refrigeration on microbiological quality. J Dairy Sci 97:3314-3320

Vadivambal R, Jayas D (2007) Changes in quality of microwavetreated agricultural products: a review. Biosyst Eng 98:1-16

Wheat Marketing Centre (2008) Wheat and flour testing methods: a guide to understanding wheat and flour quality, version 2 . Wheat Marketing Centre, Oregon

Yilmaz I, Yetim H, Ockerman H (2002) The effect of different cooking procedures on microbiological and chemical quality characteristics of Tekirdag meatballs. Nahrung/Food 46:276-278

Zenklusen MH, Coronel MB, Castro MÁ, Alzamora SM, González HHL (2018) Inactivation of Aspergillus carbonarius and Aspergillus flavus in malting barley by pulsed light and impact on germination capacity and microstructure. Innov Food Sci Emerg Technol 45:161-168

Publisher's Note Springer Nature remains neutral with regard to jurisdictional claims in published maps and institutional affiliations. 